\title{
Police perceptions of prejudice: how police awareness training influences the capacity of police to assess prejudiced motivated crime
}

\author{
Toby Miles-Johnson ${ }^{a}$, Lorraine Mazerolle ${ }^{b}$, Sharon Pickering ${ }^{c}$ and Paul Smith ${ }^{a}$

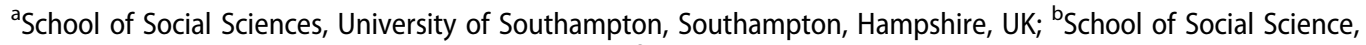 \\ University of Queensland, Brisbane, QLD, Australia; 'School of Political and Social Inquiry, Monash University, \\ Melbourne, VIC, Australia
}

\begin{abstract}
Prejudice motivated crime (PMC) is defined as crimes motivated by bias, prejudice or hatred towards members of particular groups, communities and individuals. To understand how police awareness training facilitates or constrains the capacity of police officers to appropriately classify and respond to PMC, data were collected from a population of Police Recruits (PRs) and Protective Service Officers (PSOs) $(N=1609)$ to ascertain their perceptions of PMC pre- and post-PMC awareness training. These were used in a logistic regression model to identify factors explaining whether PRs and PSOs would identify a vignette/ scenario as a PMC. We found PRs and PSOs were more likely to correctly identify a PMC scenario than a control scenario, but only $61 \%$ as likely to identify an incident as PMC post-PMC awareness training after accounting for other variables. We argue that awareness training programmes need to be more aligned to the specific needs of policing in diverse societies.
\end{abstract}

\section{ARTICLE HISTORY}

Received 29 April 2016

Accepted 21 June 2016

\section{KEYWORDS}

Police; training; prejudice; recruits; vignettes

\section{Introduction}

Prejudice Motivated Crimes (PMCs) are crimes motivated by prejudice or hatred towards a person or a group because of a particular characteristic such as sexual orientation, gender identity, religion, race, sex, age, disability or homelessness. Also known as 'Hate Crime' the definition of PMC in different countries can vary between states and police organisations, which is attributed to the discretion local law enforcement agencies possess, the ambiguity of law and the surplus of legal definitions of PMC (Grattet and Jenness 2005, p. 893). Training police to appropriately respond to PMC, and other complex issues such as drug and alcohol problems, mental health issues and domestic violence (Hails and Borum 2003, Sim et al. 2013), is typically undertaken in the context of specialised training courses at police academies (McDevitt et al. 2002, Garland and Hodkinson 2014, Miles-Johnson 2015).

However, PMC officer training programmes that focus on the needs of individual PMC victims lack consistency in approach (Bartkowiak-Theron and Asquith 2014). Many PMC police awareness training programmes use information from other agencies, some follow statewide guidelines, and others gather information from national professional bodies or groups within their own community (Grattet and Jenness 2005). Research shows that many officers lack the required specialist knowledge to respond to victims of PMC and are unable to adequately distil and transmit the meaning of PMC (Grattet and Jenness 2005, Garland and Hodkinson 2014). Specific police awareness training courses 
are found to be inadequate (see Gover et al. 2011, Lonsway and Archambault 2012, Spohn and Tellis 2012, Miles-Johnson 2015, Renzetti et al. 2015), particularly those that are focused on PMC awareness.

At the academy level, little research exists that explores how police organisations incorporate PMC recognition, education and instruction into their training programmes (Skogan et al. 2015). Many police organisations are including PMC within their training curriculum but the actual length and specificity of the training techniques used to enable police officers to recognise and respond to PMC varies between police organisations ${ }^{1}$ (Miles-Johnson 2015). Mason et al. (2015) suggest that PMC instruction and training include awareness of obvious groups as possible victims of PMC, and specific instruction regarding operational factors relating to the practical policing challenges of responding to PMC in the field such as definition, identification and recording of PMC.

This paper examines how police awareness training influences the capabilities of police officers to correctly categorise and respond to PMC. Using a survey-based experimental method, we collected data from a population of 1609 police officers (comprising Police Recruits (PRs) and Protective Service Officers $^{2}$ (PSOs)) to understand their perceptions of PMC, pre- and post-awareness training. Using a logistic regression model, we examine the effects of pre- and post-PMC awareness training on the police officer's perceptions of PMC Recognition; PMC Handling; PMC Attendance; PMC Reporting; and PMC Arresting. We begin the paper with an overview of the extant literature informing our study. We then provide a brief overview of the survey-based experimental method and 18 victimisation scenarios used to determine officer perceptions and responses to incidents of PMC. Our results show that the majority of police officers are likely to recognise the factors that facilitate or constrain their capacity to appropriately classify and deal with PMC. Our findings also suggest that many police officers fail to recognise and categorise an incident of PMC post-awareness training, and that overall the PMC awareness training programme did not improve the officer's awareness of the diversity of PMC crimes or the severity of the issue.

\section{Background literature}

PMC victimisation is defined in relation to the diversity of an individual's identity based on characteristics such as race, ethnicity and religion, and sex of victim, sexuality, and gender. Previous research indicates that people identify with their race first (the superordinate identifier) before their ethnicity (subordinate identifier) (Lee and Bean 2004, Cokley 2007) and religion (subordinate identifier) (Edwards 2008). Therefore, a superordinate identity such as race, and subordinate identity markers such as ethnicity and religion are typically cited as the motivation behind PMC victimisation (Chakraborti 2015). Although a superordinate identity (or identifier) can be based on either the sex or race of a person (Kane 2010), in instances where a group of people form a minority group because of their race, race becomes the superordinate identifier over the sex of an individual (West et al. 2009).

Previous research also indicates that people identify with their sex first (the superordinate identifier) (Egan and Perry 2001) before their sexuality (subordinate identifier) and before their gender expression (subordinate identifier) (Felsenthal 2004). Therefore, a superordinate identity marker such as sex and the subordinate identity markers such as sexuality and gender expression can also be causal triggers underlying PMC victimisation (Miles-Johnson 2013). While the intersections of the concepts of race, ethnicity and religion, and sex, sexuality and gender indicate that they are all individual markers of identity, when expressed as a collective grouping, they can also be used as a marker for identity in relation to group-membership. However, when used collectively the identifiers race and sex become the superordinate identity markers over ethnicity and religion, and become the superordinate identity markers over sexuality and gender expression. In this way, PMC victimisation can be related to both individual identity characteristics and group characteristics relating to group-membership.

Police interaction with members of diverse communities adds complexity to the provision of services offered by police departments. The demands on the police are no longer straightforward in terms of law enforcement. Policing is shaped by mission statements, targets and goals reflecting 
various expectations of community members (Walker and Archbold 2013). In modern societies, police departments are expected to meet the needs of multiracial and multicultural communities, and offer services that reflect the high diversity of communities (Alpert et al. 2014). Policing diverse groups of people creates an array of challenges for police departments who are increasingly involved in addressing social problems created by the changing composition of communities.

Crime and unrest often expose underlying intergroup tensions in diverse communities (Mason et al. 2015). Frequently tested by the need to provide adequate and appropriate services to populations that are dynamic in their racial, ethnic, religious, social and cultural structure, police officers regularly moderate complex intergroup relationships and manage intergroup tensions fuelled by prejudice (President's Task Force on 21 st Century Policing 2015). Increases in the number of incidents of PMC put police departments under pressure to ensure that officers are trained appropriately to resolve intergroup tension, and to interact correctly with minority group members. Yet how police engage with members of diverse communities is criticised in much of the extant literature (Constable and Smith 2015) and raises questions regarding whether or not current police awareness training is adequate in terms of how PMC is policed.

Recent reports examining police awareness training find that while most police officers are clear on what constitutes a crime and know the procedures to follow; current training programmes do not equip them to deal with complicated cases of PMC. According to the 2012 'Training against Hate Crimes for Law Enforcement' (TAHCLE) report (Organization for Security and Cooperation in Europe 2012, p. 6), training for PMC awareness should aim to help police officers ensure effective investigation and prosecution of $\mathrm{PMC}$, and also enable police officers to understand the context and special attributes of PMC. Yet, many investigative bodies examining the effectiveness of PMC training have criticised these courses for a lack of sustainability (Garland 2015). In the United States (US), the Federal Bureau of Investigation and the Center for Problem-Oriented Policing (2015) argue that police departments which train their officers to investigate PMC seriously are more likely to have officers that consistently enforce PMC laws and adhere to the police department's policies in addressing PMC. However, many police departments are not effectively training police officers to treat PMC differently to regular crimes. In the United Kingdom, Her Majesty's Inspectorate of Constabulary also found that there was an absence of reliable and robust evaluations of PMC training courses (Docking and Tuffin 2005).

The lack of consistent and effective training in PMC has led to much criticism regarding the implementation of PMC training as programmes that are merely rolled out when the subject is 'flavour of the month', and/or perhaps precipitated by a significant event such as the murders of Matthew Shepard and James E. Byrd Jr which inspired The Hate Crime Prevention Act signed into US law in 2009 or the Stephen Lawrence Inquiry (an official report published in 1999 of an inquiry into the racially motivated murder of British man Stephen Lawrence). Previous research by Docking and Tuffin (2005) and Miles-Johnson (2016) also shows that many police departments possess insufficient policies to either implement diversity training or sustain PMC training programmes on a systematic basis over long periods. Rather, it would seem that PMC training programmes often exist on their own, as 'stand-alone' exercises that are often not followed up in staff appraisals or by refresher courses offered by police organisations (Miles-Johnson 2015).

Effective police awareness training for PMC assists officers to recognise particular characteristics of PMC victimisation (Chakraborti 2015). According to the FBI Uniform Crime Reporting (UCR) Programme (2015), police officer training in PMC should enable an officer to recognise how an offender's criminal act must have been motivated, in whole or in part, by his or her prejudice. It should also enable an officer to recognise sufficient objective facts that will lead a reasonable and prudent person to conclude that the offender's actions were motivated, in whole or in part, by bias. The US Department of Justice (2008) states that key components of PMC training should address the range of issues relevant to PMC such as deterrence and prevention, the needs of the communities and the victims, investigation and reporting of PMC, and prosecution of PMC in the criminal justice system. In addition, the U.S. Office for Victims of Crime (2015) states that effective PMC training will facilitate 
correct officer handling of PMC, thereby providing law enforcement officials with up-to-date strategies to use in identifying bias crimes and appropriate actions to deter and investigate PMC.

Previous research shows that police awareness training programmes must be concentrated on preparing police officers with cognitive skills to perform their duties equitably, and should therefore be provided with great care and consistency since they can serve to signpost the type of operational procedures that police officers may face (Casey 2000). The capacity of police officers to correctly recognise and identify PMC seeks to improve the often poor and unstable relationship police have with minority group members (Cherney 1999, Bernstein and Kostelac 2002, Miles-Johnson 2013, 2015). The ability of police officers to distinguish and categorise PMC is, therefore, hypothesised to improve positive intergroup relations particularly considering how interaction with minority groups shapes police perceptions of minority group members, and equally, minority group members' perceptions of the police (see Murphy and Cherney 2012, Sargeant et al. 2014).

Members of minority groups have frequently criticised police officers for their lack of awareness regarding specific types of victimisation (Miles-Johnson 2015). An officer who responds to an incident of suspected PMC is responsible for correctly determining whether or not there is any indication that the offender was motivated by bias. According to the FBI Hate Crime training manual (2015), when responding to a suspected incident of PMC an officer must quickly evaluate what has happened, take any necessary action to stabilise the situation, and correctly classify a PMC because PMC victimisation can cause extreme psychological stress to both the victim and the victim's community, and failure to correctly classify a PMC can reduce confidence levels in the police.

Diminished confidence in police officer capacity to accurately categorise PMC can undermine community cohesiveness and strain ties between the police and members of society (see Craig and Waldo 1996, Green et al. 1998, Balboni and McDevitt 2001, California Attorney General's Civil Rights Commission on Hate Crimes 2001, International Association of Chiefs of Police 2002, Cogan 2002, Kercher et al. 2008). Policing minority groups is already challenging for police departments who are faced with greater diversity in cultural norms, values, identities and attitudes towards police and the law (see Brown and Benedict 2002, Schafer et al. 2003, Schuck et al. 2008, Van Craen 2012, Tyler 2011, Miles-Johnson 2013, Murphy 2013). Research shows that minority group members are typically less confident in police, less likely to cooperate with police, less likely to report their own victimisation and less likely to call police for help than non-minority group members (Bird 1992, Skogan 2006, Cherney and Chui 2009, Murphy and Cherney 2012, Miles-Johnson 2013, 2015, 2016, Murphy 2013). This is problematic for police departments who are under pressure to effectively engage with members of the community who are less likely to trust the police than other members of society (see Tyler 2001, 2005, Tyler et al. 2015). Yet good community relations with all members of the public are essential to good policing (Rowe and Garland 2013).

Responding to specific types of victimisation ensures public safety, maintains order and is a direct response to citizens' requests for police service (International Association of Chiefs of Police 2002). Despite improvements in PMC awareness, the decision to respond to victimisation and report a crime with any potential bias motivation is ultimately at the discretion of the police department (Nelson et al. 2015). Although police departments are encouraged to respond to suspected bias incidents and hate crime to ensure no crime has been committed or rule out bias motivation, without PMC awareness training police officers have difficulties in defining what acts constitute a PMC because of vague departmental guidelines and/or definitions of such events (Martin 1995, Boyd et al. 1996, Shively 2005, Nelson et al. 2015).

Recognising the difference between a non PMC and a PMC is pivotal in the way that police officers respond to bias crime. Research by Garofalo and Martin (1991) found that police officers were more likely to make an arrest for a PMC when the motivation of the offender was based on sexual orientation or race in comparison to other categories examined. Research by Lyons and Roberts (2014) also found that police officers were more likely to recognise PMC when the profiles of the victims and offenders fit conventional stereotypes and not when the characteristics of the victim or offender 
were instantly recognisable. Training police officers to correctly distinguish PMC victimisation where the offender intentionally selects the victim because of the victim's actual or perceived race, ethnicity, religion, gender, disability or sexual orientation highlights the complexities of police understanding and recognising its many forms. Identifying the variations between PMC and non PMC also raises thought-provoking debate regarding the amount to which police recognition of PMC can (in and of itself) provide the means to address the wider institutional dynamics of inequalities in power relations between the police and minority group members (Rowe 2013, Miles-Johnson 2015).

Yet many police departments are concerned that police officers are recalcitrant in their attitudes towards police training and occupational competence when awareness training is linked to potential future interaction with diverse minority communities (Moran and Sharpe 2004). Skogan et al. (2015) highlights the important role that police training can play, particularly in relation to the operationalisation of components of procedural justice such as fair treatment of individuals when police interact with members of the public and minority groups (see also UK Police College Manchester experiment). Research by Miles-Johnson $(2013,2015,2016)$ also finds that specific types of police awareness training in relation to minority group engagement is vital if minority group members are going to perceive the police and policing in a positive way. However, Skogan et al. (2015) argue that very little is known about the short- or long-term effects associated with police training of any type and that police departments themselves often issue post-training surveys to police officers that assess pieces of the training; although 'before and after' studies of the effects of training are missing from the literature.

Part of ongoing investment in training reforms with members of minority groups (and victims of PMC) includes the deployment of police officers within specialist police liaison units (PLUs) whose role it is to enhance the delivery of police services to specific groups within society. In the United Kingdom, United States and Australia, there has been an increase in the number of police units established to improve community relations with police, and an increase in the number of specially trained police officers deployed by police departments to improve the relationship between members of particular communities and police departments (Cherney and Chui 2010, Allen 2014, Campbell 2014, Nelson et al. 2015). Many of the PLUs were created to improve police engagement and interaction with members of minority groups and as such form part of a focused strategy to improve cultural competency of police services. However, the types of police officers within the PLUs are often not sworn police officers and do not possess statutory powers similar to formal uniform police. Their primary role is to engage minority group members and assist sworn police officers when coming into contact with people of particular ethnic, racial and cultural backgrounds, particularly during times of PMC victimisation (Cherney and Chui 2010, Allen 2014, Campbell 2014, Nelson et al. 2015).

Little attention, however, is given to how police awareness training programmes impact on police relations with minority communities. Rowe (2013) argues that training programmes are often overlooked in terms of how they impact on police work in general, and this problem is imitated in the absence of ongoing training procedures regarding interaction with minority groups. Other than training police officers to recognise victims of crime identified by racial difference, research also notes the absence of diverse victim identifiers within PMC awareness training (Murphy 2013, Miles-Johnson 2015). How police officers respond to operational training techniques specifically created for PMC has not been investigated, mainly because police awareness training procedures regarding PMC are still in their infancy (Allen 2014, Campbell 2014, Miles-Johnson 2015, Nelson et al. 2015). Research by Wheller et al. (2013) determined that when training police officers to interact with victims of crime, positive police attitudinal responses to vignette/scenarios had constructive effects on the interaction of crime victims who were later served by police officers trained in this way.

\section{Research site}

Entry level police officers in one Australian jurisdiction were given 33 weeks of police training before commencing their employment. PMC awareness training formed part of the curriculum and was 
typically delivered in the 19th week of training over one four-hour session, within one day. Incorporating lectures and operational skills, PMC awareness training was delivered to the PRs by senior police personnel. ${ }^{3}$ PMC awareness training covered cross-cultural and community diversity issues specifically related to bias or hate-related crimes where offences target a person's or group's gender, race, religion or sexual orientation. The training focused on defining PMC, reviewing the most common types of reported and committed PMCs, strategies to improve PMC-based reporting by victims, and the operational skills and tactics needed to identify PMC in order to decrease frequency and increase victim reporting. Throughout the training programme there was a clear focus on the operational context in which PMC needs to be handled. ${ }^{4}$ All of the PRs and PSOs were given identical training sessions regarding PMC awareness and these were delivered by the same training team over the course of the data collection period.

\section{Data and methods}

Our study employs PMC vignette/scenarios to better understand: first, how police might respond to PMC victimisation; second, whether or not training procedures can manipulate the way in which police recognise and handle PMC; and third, how police would attend, report, and then arrest an offender of PMC. Based on real-life incidents of PMC victimisation, the vignette/scenarios were constructed around incidents of physical and verbal assault. The vignette/scenarios were approved by the police organisation. Senior police officers with expertise in PMC helped the research team identify correct responses to the PMC incidents. This strengthened the ecological validity of the study and enabled inter-rater reliability. The PMC incidents were also contextualised to one specific geographic area known to the police organisation to be a hotspot for PMC victimisation. The use of vignette experiments has been an enduring element of research (see Tsoudis and Smith-Lovin 1998, Goudriaan and Nieuwbeerta 2007, Haas et al. 2012) and can determine how several factors simultaneously affect police responses to certain types of crime and victimisation (Tolsma et al. 2012). Therefore, using PMC vignette/scenarios to understand police attitudinal responses to PMC victimisation can determine whether or not training procedures influence the way in which police recognise and handle PMC.

\section{The sample/population}

The pre-training survey, in its entirety, was provided to the PRs and PSOs prior to the start of the first wave of PMC training via Qualtrics Survey Online Software (on Ipads ${ }^{5}$ ). The post-training survey (also in its entirety and provided in the same way via Ipad) was administered four hours later at the end of the training session. The survey was successfully administered to 60 classes in total which included 37 groups of PRs and 29 groups of PSOs. The final sample comprised 1609 recruits which included 946 PRs and 663 PSOs. There were more male than female participants in the final sample, with 1215 males and 370 females completing the pre- and post-training sessions.

The ages of the participants ranged from 18 to 65 years of age. The average age of all participants was 30 years of age. However when examined by class type, the average age of the PRs was 28 years of age and the average age of the PSOs was 32 years of age. In the final dataset, only two PR participants identified as Aboriginal, with three PRs and one PSO identifying as both Aboriginal and Torres Strait Islander. Only a small number of the participants considered themselves as a member of a minority racial group $(n=180)$ or as a member of a minority ethnic group $(n=178)$. The majority of the participants identified as heterosexual $(n=1502)$ and the majority of the participants were in a relationship at the time of the research $(n=1180)$. Prior to completion of training at the police academy, the majority of the participants were educated beyond high school level with over a quarter of the participants holding a certificate or diploma $(n=462)$, and over a quarter of the participants completing 'Year 12' or their 'Senior Year' $(n=458)$. Almost a quarter of the participants had completed a Bachelor degree $(n=335)$. Only one participant (a PSO) indicated that they did not attend school prior to completing training at the police academy. 
The pre-training survey comprised 22 items (seven identity-related questions and three scenarios with five fixed questions). The post-training survey comprised 81 items, 7 identity-related items, 44 items assessing perceptions of trust (adapted from Smith et al. 1998), socialisation, interaction, professional engagement, professional conduct, rules and regulations (adapted from Moynihan 2010), living and work choices with people identified by differences in race, ethnicity, religion, sex, sexuality and gender difference (adapted from National Security and Preparedness Survey 2012), and three scenarios with 5 fixed questions and 15 demographic items (adapted from Miles-Johnson 2013, 2015, 2016).

\section{Outcome variable}

In this analysis, we are interested in whether the training makes the trainees more or less likely to identify an incident as a PMC. Therefore, we take the outcome variable as a binary one based on the PR/PSO's 'yes' and 'no' answers to whether a vignette scenario would be treated as a PMC (Yes $=1, \mathrm{No}=0$ ) for the purposes of recognition, handling, attending, reporting and arresting. Each $\mathrm{PR} / \mathrm{PSO}$ received three scenarios, randomly allocated in the survey, and delivered in both the preand post-PMC awareness training sessions. Outcome variables for all questions and for pre- and post-training responses were stacked to make a large dataset. Indicator variables (see Predictors, below) were added to the outcome variables to identify the situation (pre-/post-, etc.) from which they originated.

\section{Predictor variables}

The indicator variables are potential predictors of the outcome. The indicator variable 'PMC Scenario Intensity' records the different levels of intensity of the PMC scenario (ranging in intensity of incident of verbal and or physical abuse) described implicitly or explicitly across each of the six vignette/scenarios. It has six levels; $0=$ not a PMC (the reference category), and 1-5 for increasing intensity. The indicator variable 'PR or PSO' shows whether the training was delivered to classes of PRs $(=0)$ or PSOs $(=1)$. The indicator variable 'Police PMC Response' shows whether the question concerned the recognition (the reference category), handling, attending, reporting or arresting of PMC.

Further variables relating to characteristics of the participants were also included in the dataset: 'Gender' (male $=0$, female $=1$ ), 'Race' (yes - member racial group $=1$ and no - member racial group $=0$ ), 'Ethnicity' (yes - member ethnic group $=1$ and no - member ethnic group $=0$ ) and 'Age' (18-30 years of age $=0$ and $30+$ years of age $=1)$. A logistic regression model was built from this information to identify the variables (predictors) mostly closely related to the outcome. Prior to analysis, collinearity diagnostics were run on all of the predictors in the model. A check for multicollinearity indicated that the set of predictor variables were strongly related to the dependent variable but not to each other, which is ideal for a logistic regression ( $O^{\prime}$ brien 2007). There were no tolerance values less than .1 and the variance inflation factor values indicated that the model had not violated the multicollinearity assumption.

\section{The vignette/scenarios}

Using randomised vignette experiments can be a way to overcome ethical, practical and methodological limitations associated with experimental studies on perception (see Kim and Hunter 1993, Goudriaan and Nieuwbeerta 2007). When randomly assigned to respondents in a study, the participants can imagine themselves in one or more scenarios and then respond to various questions or stimuli (Goudriaan and Nieuwbeerta 2007). The randomisation allows the researchers to avoid selection biases. An advantage of using vignette experiments is that participant behaviour within specific contexts and hypothetical situations can be determined (Evans et al. 2015). 
Previous research by Leeper et al. (2006) argues that vignettes may not be comparable to data collected in real-life situations and that what is captured is a participant's intention to behave a certain way and not actual behaviour. Yet other studies have found a strong correlation between intentions captured by vignette research and real-life behaviour (Kim and Hunter 1993, Goudriaan and Nieuwbeerta 2007). Previous studies have also noted that in order to minimise the limitations of vignette studies, it is important to design scenarios that participants perceive to be realistic, by describing situations and contexts that are familiar to the participants (Evans et al. 2015). Therefore, we constructed 18 unique victimisation vignette/scenarios $\left(N_{\mathrm{s}}=18\right)$ based on real-life incidents of assault and verbal abuse previously recorded by police officers. The 18 vignette/scenarios were clustered into three groups of six scenarios which we labelled scenario 1 (Race, Ethnicity and Religion), scenario 2 (Sex, Sexuality and Gender) and scenario 3 (Race, Ethnicity and Religion - location specified). Each group of six scenarios contained one control scenario and five variations on the control scenario ranging in intensity of incident of verbal and or physical abuse (see Appendix).

\section{Randomisation}

Each individual class of recruits was randomly allocated a set of three scenarios in their respective preand post-surveys. The allocation of the three scenarios was conducted using a randomised design so that each of the scenarios appeared in an equal number of classes (10 classes) across the total group of 60 training sessions, although the design of the model was not balanced across individuals in relation to their inclusion in either the PR or PSO training groups. Each combination of scenarios (one race/ethnicity/religion, one sex/sexuality/gender and one race/ethnicity/religion - location-specific) was not used more than once and each group of PRs and PSOs received three scenarios pre- and post-training.

The control vignette was used 30 times out of the 60 classes. About 17 classes got one control vignette, five classes got two control vignettes and one class got all three. Each scenario was followed by five fixed items, identically measuring how each PR and PSO would respond and report an incident of PMC categorised in three situations: the first scenario/situation specified by the victims race, ethnicity and religion, the second scenario/situation specified by the victims sex, sexuality and gender characteristics, and the third scenario/situation specified by the victims race, ethnicity and religion in a location known in the state to be a hotspot for PMC. Each PR and PSO was asked to read the scenario and indicate whether he or she recognised the crime as an incident of PMC, whether he or she would handle this case as a PMC, whether he or she would attend the incident, whether he or she would report the incident as a PMC, and whether he or she would arrest the offender for committing a PMC. The responses to the five fixed items relating to each of the scenarios were coded as 'yes' or 'no'.

Although all four possibilities for combinations of 'yes' and 'no' answers were analysed in the dataset, it was anticipated that the PMC awareness training would encourage people to move from pre-training 'no' answers to post-training 'yes' answers in terms of whether or not each PR and PSO would recognise the crime as an incident of PMC, would handle the case as a PMC, whether they would attend the incident, whether or not they would report the incident as a PMC, and whether or not an offender would be arrested for committing a PMC.

Since each of the five scenarios included within each clustered group of six scenarios vary in intensity to the control scenario, the effects of the vignettes were separately estimated so that an assessment of the impact on the probability of a 'yes' response to any particular scenario could be determined. The randomised design of the model meant that these effects could be estimated with good statistical power. This allowed for an analysis regarding whether or not the PRs' and PSOs' reactions were in line with the variations of intensity of PMC outlined in the scenarios.

\section{The first scenario/situation (Race, Ethnicity and Religion)}

To help examine the first scenario/situation, we defined 'Race' as a human population considered distinct based on physical characteristics, 'Ethnicity' as a term which represents social groups with 
a shared history, a sense of identity, geography and cultural roots which may occur despite racial difference, and 'Religion' as a collection of cultural systems, belief systems, and worldviews that relate humanity to spirituality and, sometimes, to moral values (Cokely 2007). Research into dominant groups situated in Australia identified by their race, ethnicity and religion indicated that the Sudanese-African population was one of the largest growing migrant populations (Australian Bureau of Statistics 2011); as such a Sudanese-African identifier was used in this scenario. Although a superordinate identity (or identifier) can be based on either the sex or race of a person (Kane 2010), in instances where a group of people form a minority group because of their race, race becomes the superordinate identifier over the sex of an individual (West et al. 2009). Therefore, the Sudanese-African population is identified primarily by its superordinate identity (race) and then by the differences they have in their subordinate identifiers (for example differences in ethnicity and religion). Accordingly, research indicated that the largest contingent of Sudanese-African migrants in Australia are from North Africa, and this group comprises a majority population of ethnic Arabs whose religious beliefs and practices under Islam are colloquially known (and identified) as Muslim. Thus, the concept of race is based on a SudaneseAfrican identity, the concept of ethnicity is based on an Arab identity and the concept of religion is based on a Muslim identity.

\section{The second scenario/situation (Sex, Sexuality and Gender)}

Research into dominant groups situated in Australia identified by their differences in sexuality and gender (and sexed body) indicated that the gay (male) population is frequently associated with alternative expressions of gender, and typically an association is made between gay males and 'Drag Queens' (Maddison 2000). Included under the umbrella term 'Transgender', Drag Queens are typically gay men who temporarily alter their gender to appear as women for entertainment purposes (Taylor and Rupp 2004, Miles-Johnson 2013, 2015, 2016). In Australia, this type of association (likening all gay men to Drag Queens) is an association that is frequently made by heterosexual males about gay men (Wotherspoon 1991), and as such, links non-heterosexual expressions of sexuality to alternative expressions of gender. Thus, the concept for Sex is based on a male identity, the concept of sexuality is based on a gay male identity, and the concept of gender is based on a Drag Queen identity.

\section{The third scenario/situation (Race, Ethnicity and Religion - location specified)}

In the third scenario/situation specified by the victim's race, ethnicity and religion in a location known in Australia to be a hotspot for PMC, the superordinate identity marker was changed. In this scenario, the superordinate identity marker was Ethnicity, and the subordinate identity markers were Religion and Race. Within the 2011 national census, research into dominant groups situated in Australia indicated that Australia's Jewish population had grown significantly in size (Australian Bureau of Statistics 2011); as such a Jewish identifier was used in this scenario. The Jewish population predominantly comprises Ashkenazic Jews, who are Jews that originated from eastern France, Germany and Eastern Europe. Within the Ashkenazic Jewish population are the Chassidim (or Chassidic Jews) who represent a small but very active and distinctive orthodox minority group (Rutland 2005). Chassidic Jews are probably considered the most colourful and distinctive of Australian Jews. Consequently, noticeable by their distinct appearances, Chassidic Jews are often mistaken for a racial group rather than a religious group by members of the public (Rutland 2005). Therefore, a subordinate identity marker such as religious identity is often used over and above a superordinate identity (such as race) to classify or to identify Jewish people. Thus, the concept for Race is based on an Ashkenazic Jew identity, the concept of ethnicity is based on a Chassidim Orthodox Jew identity and the concept of religion is based on Judaism. 


\section{Results}

The overall percentages of 'yes' and 'no' responses given by the officers pre- and post-awareness training are shown in Table 1. There is an overall rise in percentage of vignette incidents identified as PMCs after the training, and the numbers of no $\rightarrow$ yes responses is larger than the number of yes $\rightarrow$ no responses. However, this is a very complex dataset with the intensities and scenarios potentially having an effect on the outcomes.

The logistic regression modelling allows us to assess the impact of the different variables in the dataset, including the PMC awareness training, on the officer's scores. Table 2 (below) shows the full model containing all the predictors; the model fit was statistically significant $X^{2}(15, N=$ $47,548)=14,604.22, p<.001$. The model as a whole explained between $26.4 \%$ (Cox and Snell $R$ square) and $36.6 \%$ (Nagelkerke $R$ square) of the variance in the outcome variable, and correctly classified $77 \%$ of cases. As shown in Table 2, all of the independent variables apart from Race made a unique statistically significant contribution to the model.

The model distinguishes the factors that facilitate or constrain the capacity of police officers to appropriately classify and deal with PMC. The odds ratio for 'post-test' indicates that, taking all other variables in the model into account, post-training responses are only $61 \%$ as likely to be 'Yes' as pre-training responses. In other words, training makes PRs and PSOs less likely to identify a vignette/scenario as a PMC. This effect is significant $(p<0.001)$ using a Wald test (Table 2$)$.

We can also examine the effects of other variables in the model. We expected the intensity parameters to show a monotonic increase in odds because the intensity of PMC incidents was designed to increase over the levels. Reassuringly, PRs and PMOs are between 2.35 and 14.12 times more likely to identify an incident as a PMC in vignette/scenarios where a PMC was indicated than in the control. However, we see that the odds ratios for levels 2 and 4 are similar, and lower than for levels 3 and 5. This shows that the participants did not interpret the intensity of the incidents in the expected way, and were not more likely to answer 'Yes' as the intensity of PMC increased, but more likely to answer 'Yes' for levels 3 and 5 compared with levels 2 and 4 . There is also a noticeable difference in the parameters relating to the question types, where the participants were more likely to answer 'Yes' to the reporting of PMC questions than to the other types (recognition, handling, attending and arresting), as indicated by the larger odds ratio (Table 1 ).

\section{Discussion and conclusion}

Using an experimental vignette design, our research explored police officer perceptions of PMC and their capacity to appropriately classify PMC incidents pre- and post-PMC awareness training. Overall, the results show that PRs and PSOs were less likely to record an incident as PMC post-PMC awareness training.

This study, however, has several limitations. First, there are limits to the use of vignettes in research because they only mimic reality, vignettes may not be comparable to data collected in real-life situations and what is captured is a participant's intention to behave a certain way and not actual behaviour. Second although previous research has determined that vignettes are adequate to combine independent variables (Maguire et al. 2015), other victim and offender dimensions might influence a police officer's perception of whether or not a PMC has occurred, such as victim provocation, an offenders use of drugs and alcohol, and the mental health of an offender. Other situational variables might also influence a police officer's opinion, such as possession of a weapon or bystander presence.

Table 1. Total 'yes' and 'no' responses to the scenarios - pre- and post-awareness training.

\begin{tabular}{lcc}
\hline Response & Pre (\%) & Post (\%) \\
\hline No & 38.1 & 30.0 \\
Yes & 61.9 & 70.0 \\
\hline
\end{tabular}


Table 2. Logistic regression assessing the pre- and post-differences in PMC training scores.

\begin{tabular}{|c|c|c|c|c|c|c|c|c|}
\hline & \multirow[b]{2}{*}{$B$} & \multirow[b]{2}{*}{ SE } & \multirow[b]{2}{*}{ Wald } & \multirow[b]{2}{*}{ df } & \multirow[b]{2}{*}{$p$} & \multirow[b]{2}{*}{ Odds ratio } & \multicolumn{2}{|c|}{$\begin{array}{l}95.0 \% \mathrm{Cl} \text { for Odds } \\
\text { ratio }\end{array}$} \\
\hline & & & & & & & Lower & Upper \\
\hline Post-Training Score & -0.50 & .02 & 471.38 & 1 & .000 & 0.61 & 0.58 & 0.64 \\
\hline PMC Scenario Intensity & & & 6577.53 & 5 & .000 & & & \\
\hline PMC motivation unspecified (1) & 0.86 & .04 & 495.28 & 1 & .000 & 2.35 & 2.18 & 2.54 \\
\hline PMC motivation implied ( 2 ) & 2.08 & .04 & 2792.34 & 1 & .000 & 7.97 & 7.38 & 8.61 \\
\hline PMC motivation very implied (3) & 2.61 & .04 & 3849.04 & 1 & .000 & 13.62 & 12.54 & 14.79 \\
\hline PMC motivation explicit (4) & 2.12 & .04 & 2807.11 & 1 & .000 & 8.33 & 7.70 & 9.01 \\
\hline PMC motivation very explicit (5) & 2.65 & .04 & 4043.70 & 1 & .000 & 14.12 & 13.02 & 15.32 \\
\hline PR \& PSO by Class & -0.36 & .03 & 203.94 & 1 & .000 & 0.70 & 0.66 & 0.73 \\
\hline Gender & 0.08 & .03 & 8.24 & 1 & .004 & 1.08 & 1.03 & 1.14 \\
\hline Race & 0.02 & .05 & 0.09 & 1 & .770 & 1.02 & 0.91 & 1.13 \\
\hline Ethnicity & 0.22 & .06 & 16.17 & 1 & .000 & 1.25 & 1.12 & 1.39 \\
\hline Age & 0.12 & .02 & 27.05 & 1 & .000 & 1.13 & 1.08 & 1.19 \\
\hline Police PMC Response Question Type & & & 3521.55 & 4 & .000 & & & \\
\hline Handling & 0.18 & .03 & 28.65 & 1 & .000 & 1.19 & 1.12 & 1.27 \\
\hline Attending & 0.16 & .03 & 23.61 & 1 & .000 & 1.17 & 1.10 & 1.25 \\
\hline Reporting & 3.45 & .06 & 3314.37 & 1 & .000 & 31.56 & 28.06 & 35.49 \\
\hline Arresting & 0.14 & .03 & 19.02 & 1 & .000 & 1.15 & 1.08 & 1.23 \\
\hline Constant & -1.16 & .05 & 581.23 & 1 & .000 & 0.31 & & \\
\hline
\end{tabular}

Third, the research was conducted with a sample of police officers in one police organisation in one Australia state. ${ }^{6}$ Further research is needed in other police organisations across Australia to determine if the findings of this study are representative of police officer opinions in general regarding PMC awareness. Fourth, this study has not examined the effects of police culture on police attitudes and behaviour, and the underlying and often negative nature of police operational culture (see Foster 2003, Skogan 2008, Stanko et al. 2012, Myhill and Bradford 2013), particularly in relation to how it may affect police officer attitudes and perceptions of PMC.

Despite the limitations, this study provides several important insights. The results indicate that the whole training process has a negative effect on police officer recognition of diverse incidents of PMC victimisation pre- and post-training, with many police officers failing to recognise and categorise an incident of PMC post-training. For example, the difference scores calculating how many police officers were able to recognise an incident of PMC pre-training and then post-training indicate that some police officers were able to recognise an incident of PMC before the training but not after, suggesting that the training may have confused their perceptions of PMC. This raises questions about the effectiveness of current PMC police awareness training and education strategies, especially since police are typically the first responders to a range of incidents, and when a PMC occurs they need to handle this type of crime appropriately because elements of victimisation are unique to victims of PMC.

While changing the frequency (and content) of PMC awareness training may help improve the capacity of police to recognise and appropriately respond to PMC incidents, other factors may also influence the PRs' and PSOs' opinions of PMC and PMC victimisation. For example, previous research by Miles-Johnson $(2015,2016)$ suggests that training programmes implemented by police organisations regarding the needs of minority group members are often subject to negative police attitudes that are reinforced by police culture, and the attitudes of superior officers conducting the training programmes. Moreover, research shows that 'operational and professional' police attitudes are formed by aspects of police culture, police training and experience with certain groups of people (see MacVean and Cox 2012). Thus, it may be reasonable to conclude that our results derive from personal prejudice or the influence of other police officers on police attitudes towards PMC. Certainly, this raises a question regarding how PMC training can improve or change police officer perceptions in these situations.

Patterson (2011) identifies how higher education contributes to police learning, and recommends partnership and collaboration between police and higher education institutions to recognise clear 
training objectives with evidence-based learning strategies. Combining such objectives may change police attitudes towards PMC. The systematic acquisition of skills, rules, concepts or attitudes towards PMC gained during evidence-based training may be utilised to predict later on-the-job performance (Goldstein and Buxton, 2014), and Wheller and Morris (2010) suggest that police training integrated into routine practice is more effective at changing an individual's attitude and behaviour than classroom-based approaches. This idea is supported by Weisburd and Neyroud (2013) who also argue that police organisations should adopt an evidence-based approach to training that are developed from best-practice responses, and which focus on how situational factors attract opportunities for crime.

Yet previous research by Myhill and Bradford (2013) and Reiner (2010) posit that many police officers are opposed to a service model of policing that replaces traditional crime fighting strategies with victim-centred approaches, and are, accordingly, reticent to reform dimensions of policing. Assuming that a number of police may not have formed perceptions of minority group members and PMC victimisation prior to the commencement of training, pre-service PMC awareness training is potentially very important in modifying police culture. Similar to findings by Renzetti et al. (2015) and Skogan et al. (2015) who argue that different training procedures are needed for different ranks of police officers, it may be that in Australian police organisations a 'one-size-fits-all' training approach implemented to officers at all levels of the police organisation is inappropriate. A more nuanced delivery of PMC awareness training should be given to senior and executive-level officers, with a focus towards exercising this awareness within the police organisation as well as externally. However, PMC awareness training alone may not be enough to change the perceptions within the police overtime.

\section{Notes}

1. Information regarding PMC training programs is lacking in the extant literature, as such a thorough critical review of the different training programs and training evaluations implemented and used by police organisations in response to PMC was not included in this paper.

2. PSOs are part of the transit safety division of the police. PSOs are employed to monitor peak hour train services and have the same operational power as an operational police officer.

3. Exact details of the PMC awareness training could not be included in this paper due to the ethics agreement protecting the police organisation from identification.

4. The PMC awareness training was based on a self-directed learning concept where the participants learnt from a broad range of experiences, stimulated by immediate and real-life policing situations. The learning outcomes of the PMC awareness training program were motivated by the internal incentives of the participants and were problem-centered.

5. All of the police recruits were instructed to complete the surveys before they were allowed to leave the classroom so there are no missing data relating to each of the responses to the scenarios, although 24 cases of demographic information vanished from the final data set when the Wifi connection at the police academy was lost.

6. Although the findings are not directly generalisable (this research can be considered a single 'case study' of Australia data), there are lessons to be learnt and implications drawn from these results, which are relevant to police organisations in other countries.

\section{Disclosure statement}

No potential conflict of interest was reported by the authors.

\section{Funding}

This work was supported by Australian Research Council [grant number \#LP110100585].

\section{References}

Allen, M., 2014. Police-reported hate crime in Canada, 2012. Juristat: Canadian centre for justice statistics, 1, 1-29. 
Alpert, G.P., Dunham, R.G., and Stroshine, M.S., 2014. Policing: continuity and change. 2nd ed. Long Grove, IL: Waveland Press.

Australian Bureau of Statistics, 2011. 2011 Census dictionary, Cat. No. 2901.0. Canberra: Australian Bureau of Statistics.

Balboni, J.M., and McDevitt, J., 2001. Hate crime reporting: Understanding police officer perceptions, departmental protocol, and the role of the victim is there such a thing as a "Love" crime? Justice Research and Policy, 3 (1), 1-27.

Bartkowiak-Theron, I. and Asquith, N., 2014. Policing diversity and vulnerability in the post-Macpherson era: unintended consequences and missed opportunities. Policing, 9 (1), 89-100.

Bernstein, M. and Kostelac, C., 2002. Lavender and blue: attitudes about homosexuality and behavior toward lesbians and gay men among police officers. Journal of contemporary criminal justice, 18, 302-328.

Bird, G., 1992. The times they are a changing: Policing multicultural Australia. In: P. Moir and H. Eijkman, eds., Policing Australia: Old issues, new perspectives. Melbourne, VIC: MacMillan, 352-383.

Boyd, E.A., Berk, R.A., and Hamner, K.M., 1996. Motivated by hatred or prejudice: Categorization of hate-motivated Crimes in two police divisions. Law and society review, 30 (4), 819-850.

Brown, B., and Benedict, W.R., 2002. Perceptions of the police: Past findings, methodological issues, conceptual issues and policy implications. Policing: An international journal of police strategies \& management, 25 (3), 543-580.

Campbell, R., 2014. Not getting away with it: Linking sex work and hate crime in Merseyside. In: Neil Chakraborti and Jon Garland eds. Responding to hate crime: The case for connecting policy and research. London: Policy Press, 55-71.

Casey, J., 2000. International experiences in policing multicultural societies. International journal of police science and management, 3, 165-177.

California Attorney General's Civil Rights Commission on Hate Crimes 2001. California attorney general's civil rights commission on human rights. Reporting hate crimes: Final report. Sacramento, CA: Attorney General's Civil Rights Commission on Hate Crimes.

Center for Problem-Oriented Policing 2015. The problem of hate crimes. Hate crimes guide No. 72. Center for ProblemOriented Policing. Available from: http://www.popcenter.org/problems/hate_crimes/ [Accessed 27 May 2016 ].

Chakraborti, N., 2015. Mind the gap! Making stronger connections between hate crime policy and scholarship. Criminal justice policy review. doi:10.1177/0887403415599641.

Cherney, A., 1999. Gay and lesbian issues in policing. Current issues in policing, 11, 35-52.

Cherney, A., and Chui, W.H., 2009. Policing ethnically and culturally diverse communities. In: A. Cherney and W.H. Chui, eds. Policing in context. Melbourne, VIC: Oxford University Press, 160-173.

Craig, K.M., and Waldo, C.R., 1996. 'So, what's a hate crime anyway?' Young adults' perceptions of hate crimes, victims, and perpetrators. Law and Human Behavior, 20 (2), 113.

Cherney, A. and Chui, W.H., 2010. Police auxiliaries in Australia: police liaison officers and the dilemmas of being part of the police extended family. Policing and society, 20, 280-297.

Cogan, J.C., 2002. Hate crime as a crime category worthy of policy attention. American Behavioral Scientist, 46 (1), $173-185$.

Cokley, K., 2007. Critical issues in the measurement of ethnic and racial identity: a referendum on the state of the field. Journal of counseling psychology, 54 (3), 224-234.

Constable, J. and Smith, J., 2015. Initial police training and the development of police occupational culture. In: P. Wankhade and D. Weir, eds. Police services: leadership and management perspectives. London: Springer International Publishing, 45-60.

Docking, M. and Tuffin, R., 2005. Racist incidents: progress since the Lawrence inquiry. London, UK: Research Development and Statistics Directorate, Home Office.

Edwards, K.L., 2008. Bring race to the center: the importance of race in racially diverse religious organizations. Journal for the scientific study of religion, 47 (1), 5-9.

Egan, S.K. and Perry, D.G., 2001. Gender identity: a multidimensional analysis with implications for psychosocial adjustment. Developmental psychology, 37 (4), 451-463.

Evans, S.C., et al., 2015. Vignette methodologies for studying clinicians' decision-making: validity, utility, and application in ICD-11 field studies. International journal of clinical and health psychology, 15 (2), 160-170.

FBI Hate Crime training manual 2015. Hate crime data collection guidelines and training manual version 2.0. Criminal justice information services (CIS) division uniform crime reporting (UCR) program. Law Enforcement Support Section.

FBI Uniform Crime Reporting (UCR) Program 2015. Uniform Crime Reports. The FBI Federal Bureau of Investigation. Available from: https://www.fbi.gov/about-us/cjis/ucr/ucr [Accessed 27 May 2016].

Felsenthal, K., 2004. Living in between. In: J. L. Chin, ed. Psychology of prejudice and discrimination, volume 3: gender and sexual orientation. Westport, CT: Praeger Press, 201-226.

Foster, J., 2003. Cop cultures. In: T. Newburn, ed. The handbook of policing. Cullompton: Willan, 196-227.

Garland, J., 2015. One step forward, two steps backward? Difficulties and dilemmas with connecting hate crime policy and research. Criminal justice policy review. doi:10.1177/0887403415601474.

Garland, J. and Hodkinson, P., 2014. 'F** king Freak! What the hell do you think you look like?' Experiences of targeted victimization among goths and developing notions of hate crime. British journal of criminology, 54 (4), 613-631.

Garofalo, J. and Martin, S.E., 1991. Law enforcement response to bias-motivated crimes. In: N. Taylor, ed. Bias crime: The law enforcement response. Chicago: University of Illinois Press, 17-33. 
Green, D.P., Strolovitch, D.Z., and Wong, J.S., 1998. Defended neighborhoods, integration, and racially motivated Crime 1. American journal of sociology, 104 (2), 372-403.

Goldstein, I.L. and Buxton, V.M., 2014. Training and human performance. In: M. D. Dunnette and E. A. Fleishman, eds. Human performance and productivity: volumes 1, 2, and, 3. London: Psychology Press, 135-178.

Goudriaan, H. and Nieuwbeerta, P., 2007. Contextual determinants of juveniles' willingness to report crimes: a vignette experiment. Journal of experimental criminology, 3, 89-111.

Gover, A.R., Paul, D.P., and Dodge, M., 2011. Law enforcement officers' attitudes about domestic violence. Violence against women, 17 (5), 619-636.

Grattet, R. and Jennes, V., 2005. The reconstitution of law in local settings: agency discretion, ambiguity, and a surplus of law in the policing of hate crime. Law and society review, 39 (4), 893-942.

Haas, N.E., de Keijser, J.W., and Bruinsma, G.J.N., 2012. Public support for vigilantism: an experimental study. Journal of experimental criminology, 8 (4), 387-413.

Hails, J. and Borum, R., 2003. Police training and specialized approaches to respond to people with mental illnesses. Crime and delinquency, 49 (1), 52-61.

International Association of Chiefs of Police (IACP) 2002. Criminal intelligence sharing: A national plan for intelligence-led policing at the local, state and federal levels, IACP Intelligence Summit. Alexandria, VA: COPS and International Association of Chiefs of Police.

Kane, A.A., 2010. Unlocking knowledge transfer potential: knowledge demonstrability and superordinate social identity. Organization science, 21 (3), 643-660.

Kercher, G.A., Nolasco, C., and Wu, L., 2008. Hate crimes. Crime Victims' Institute, Criminal Justice Center, Sam Houston State University, 16-21.

Kim, M.S. and Hunter, J.E., 1993. Relationships among attitudes, behavioral intentions, and behavior: a meta-analysis of past research, part 2. Communication research, 20 (3), 331-364.

Lee, J. and Bean, F.D., 2004. America's changing color lines: immigration, race/ethnicity, and multiracial identification. Annual review of sociology, 30, 221-242.

Leeper Piquero, N. and Piquero, A.R., 2006. Control balance and exploitative corporate crime. Criminology, 44 (2), 397-430.

Lonsway, K.A. and Archambault, J., 2012. The 'justice gap' for sexual assault cases: future directions for research and reform. Violence against women, 18 (2), 145-168.

Lyons, C.J., and Roberts, A., 2014. The difference "Hate" makes in clearing crime an event history analysis of incident factors. Journal of contemporary criminal justice, 30 (3), 268-289.

MacVean, A. and Cox, C., 2012. Police education in a university setting: emerging cultures and attitudes. Policing, 6, 16-25.

Maddison, S., 2000. Fags, hags, and queer sisters: gender dissent and heterosocial bonds in gay culture. London: St. Martin's Press.

Maguire, N., et al., 2015. Using vignette methodology to research the process of breach comparatively. European journal of probation, 7 (3), 241-259.

Martin, S.E., 1995. A cross-burning is not just an arson: Police social construction of hate crimes in baltimore county. Criminology, 33 (3), 303-326.

Mason, G., McCulloch, J., and Maher, J., 2015. Policing hate crime: markers for negotiating common ground in policy implementation. Policing and society, 1-18.

McDevitt, J., Levin, J., and Bennett, S., 2002. Hate crime offenders: an expanded typology. Journal of social issues, 58 (2), 303-317.

Miles-Johnson, T., 2013. Confidence and trust in police: how sexual identity difference shapes perceptions of police. Current issues in criminal justice, 25, 685-702.

Miles-Johnson, T., 2015. Perceptions of group value: how Australian transgender people view policing. Policing and society, 1-22.

Miles-Johnson, T., 2016. Policing diversity: examining police resistance to training reforms for transgender people in Australia. Journal of homosexuality, 63 (1), 103-136.

Moran, L.J., and Sharpe, A.N., 2004. Violence, identity and policing The Case of violence against transgender people. Criminal justice, 4 (4), 395-417.

Moynihan, M., 2010. Report summary: the ethical perceptions and attitudes of Queensland police service recruits and first year constables, 1995-2008. Brisbane, QLD: Crime and Misconduct Commission.

Murphy, K., 2013. Policing at the margins: fostering trust and cooperation among ethnic minority groups. Journal of policing, intelligence and counter terrorism, 8, 184-199.

Murphy, K. and Cherney, A., 2012. Understanding cooperation with police in a diverse society. British journal of criminology, 52 (1), 181-201.

Myhill, A. and Bradford, B., 2013. Overcoming cop culture? Organizational justice and police officers' attitudes toward the public. Policing: an international journal of police strategies and management, 36 (2), 338-356.

National Security and Preparedness Survey, 2012. The University of Queensland, CEPS ARC Centre of Excellence in Policing and Security, ISSR Institute for Social Science Research.

Nelson, M.S. et al., 2015. Hate crimes in post-9/11 Pennsylvania case characteristics and police response revisited. Race and justice, 1-22. doi:10.1177/2153368715617812. 
O'brien, R.M., 2007. A caution regarding rules of thumb for variance inflation factors. Quality and quantity, 41 (5), $673-690$.

Organization for Security and Cooperation in Europe, 2012. Hate crimes in the OSCE region - Incidents and Responses. Available from: www.osce.org/odihr/108395 [Accessed 27 May 2016].

Patterson, C., 2011. Adding value? A review of the international literature on the role of higher education in police training and education. Police practice and research, 12, 286-297.

President's Task Force on 21st Century Policing, 2015. Final report of the president's task force on 21st century policing. Washington, DC: Office of Community Oriented Policing Services.

Reiner, R., 2010. The politics of the police. Oxford: Oxford University Press, Oxford.

Renzetti, C.M., et al., 2015. Does training make a difference? An evaluation of a specialized human trafficking training module for law enforcement officers. Journal of crime and justice, 38 (3), 334-350.

Rowe, M., 2013. Race and policing. In: J.M. Brown, ed. The future of policing. London: Routledge, 120-134.

Rowe, M., and Garland, J., 2013. Police diversity training: A silver-bullet tarnished? In: M. Rowe ed. Policing beyond macpherson, issues in policing, race and society. Devon: Willan Publishing, 43-66.

Rutland, S.D., 2005. The Jews in Australia. Melbourne: Cambridge University Press.

Sargeant, E., Murphy, K., and Cherney, A., 2014. Ethnicity, trust and cooperation with police: testing the dominance of the process-based model. European journal of criminology, 11 (4), 500-524.

Schafer, J.A., Huebner, B.M., and Bynum, T.S., 2003. Citizen perceptions of police services: Race, neighborhood context, and community policing. Police quarterly, 6 (4), 440-468.

Schuck, A.M., Rosenbaum, D.P., and Hawkins, D.F., 2008. The influence of race/ethnicity, social class, and neighborhood context on residents' attitudes toward the police. Police quarterly, 11 (4), 496-519.

Shively, M., 2005. Study of literature and legislation on hate crime in America. Washington, DC: National Institute of Justice.

Sim, J.J., Correll, J., and Sadler, M.S., 2013. Understanding police and expert performance when training attenuates (vs. exacerbates) stereotypic bias in the decision to shoot. Personality and social psychology bulletin, 39 (3), 291-304.

Skogan, W., 2008. Why reforms fail. Policing and society, 18 (1), 23-34.

Skogan, W.G., 2006. Asymmetry in the impact of encounters with police. Policing \& Society, 16 (2), 99-126.

Skogan, W.G., Van Craen, M., and Hennessy, C., 2015. Training police for procedural justice. Journal of experimental criminology, 11, 319-334.

Smith, H.J., et al., 1998. The self-relevant implications of the group-value model: group membership, self-worth, and treatment quality. Journal of experimental social psychology, 34, 470-493.

Spohn, C. and Tellis, K., 2012. The criminal justice system's response to sexual violence. Violence against women, 18 (2), 169-192.

Stanko, E., et al., 2012. A golden thread, a presence amongst uniforms, and a good deal of data: studying public confidence in the London metropolitan police. Policing and society, 22 (3), 317-331.

Taylor, V. and Rupp, L.J., 2004. Chicks with dicks, men in dresses: what it means to be a drag queen. Journal of homosexuality, 46 (3-4), 113-133.

Tolsma, J., Blaauw, J., and te Grotenhuis, M., 2012. When do people report crime to the police? Results from a factorial survey design in the Netherlands. Journal of experimental criminology, 8, 117-134.

Tsoudis, O. and Smith-Lovin, L., 1998. How bad was it? The effects of victim and perpetrator emotion on responses to criminal court vignettes. Social forces, 77 (2), 695-722.

Tyler, T.R., 2001. Public trust and confidence in legal authorities: what do majority and minority group members want from the law and legal institutions? Behavioral sciences and the law, 19 (2), 215-235.

Tyler, T.R., 2005. Policing in black and white: ethnic group differences in trust and confidence in the police. Police quarterly, 8 (3), 322-342.

Tyler, T.R., Goff, P.A., and MacCoun, R.J., 2015. The impact of psychological science on policing in the United States procedural justice, legitimacy, and effective law enforcement. Psychological science in the public interest, 16 (3), 75-109.

U.S. Department of Justice 2008. Victim services report. U.S. Department of Justice - Office of Justice Programs, Office for Victims of Crime.

U.S. Office for Victims of Crime 2015. 2015 Victims of crime report. U.S. Department of Justice - Office of Justice Programs.

Van Craen, M., 2012. Determinants of ethnic minority confidence in the police. Journal of ethnic and migration studies, 38 (7), 1029-1047.

Walker, S.E. and Archbold, C.A., 2013. The new world of police accountability. 2nd ed. Los Angeles, CA: Sage Publications. Weisburd, D. and Neyroud, P., 2013. Police science: toward a new paradigm. Australasian policing, 5 (2), $13-21$.

West, T.V., et al., 2009. Superordinate identity and intergroup roommate friendship development. Journal of experimental social psychology, 45 (6), 1266-1272.

Wheller, L. and Morris, J., 2010. Evidence reviews: what works in training, behaviour change and implementing guidance? London, UK: National Policing Improvement Agency.

Wheller, L., et al., 2013. The greater Manchester police procedural justice training experiment: technical report. London: The College of Policing.

Wotherspoon, G., 1991. City of the plain: history of a gay sub-culture. London: Hale and Iremonger. 
Appendix. The vignette constructs.

\begin{tabular}{|c|c|c|}
\hline & Implicit & Explicit \\
\hline \multicolumn{3}{|l|}{ (RER) Train station Kiosk } \\
\hline Control Vignette & Vignette (3) & Vignette (5) \\
\hline $\begin{array}{l}\text { Motivation unspecified - belief } \\
\text { in victims R/E/R unspecified } \\
\text { (Control) as no words were } \\
\text { exchanged during the assault }\end{array}$ & $\begin{array}{l}\text { Motivation due to R/E/R - belief } \\
\text { the male train station kiosk } \\
\text { worker to be Sudanese- } \\
\text { African Arab Muslim }\end{array}$ & $\begin{array}{l}\text { Motivation due to R/E/R - belief } \\
\text { the male train station kiosk } \\
\text { worker to be Sudanese-African } \\
\text { Arab Muslim }\end{array}$ \\
\hline \multicolumn{3}{|l|}{ Train station Kiosk Muslim owned } \\
\hline Vignette (2) & Vignette (4) & Vignette (6) \\
\hline $\begin{array}{l}\text { Motivation unspecified - belief } \\
\text { in victims R/E/R unspecified as } \\
\text { no words were exchanged } \\
\text { during the assault }\end{array}$ & $\begin{array}{l}\text { Motivation due to R/E/R - belief } \\
\text { the male train station kiosk } \\
\text { worker to be Sudanese- } \\
\text { African Arab Muslim }\end{array}$ & $\begin{array}{l}\text { Motivation due to R/E/R - belief } \\
\text { the male train station kiosk } \\
\text { worker to be Sudanese-African } \\
\text { Arab Muslim }\end{array}$ \\
\hline \multicolumn{3}{|l|}{ (SSG) Train station } \\
\hline Control Vignette & Vignette (3) & Vignette (5) \\
\hline $\begin{array}{l}\text { Motivation unspecified - beliefs } \\
\text { in victims S/S/G identity } \\
\text { unspecified (Control) as no } \\
\text { words were exchanged during } \\
\text { the assault }\end{array}$ & $\begin{array}{l}\text { Motivation due to negative } \\
\text { perception of male's } S / S / G \\
\text { identity- believes the male to } \\
\text { be an effeminate male, gay, } \\
\text { and a 'Drag Queen' }\end{array}$ & $\begin{array}{l}\text { Motivation due to negative } \\
\text { perception of male's } S / S / G \\
\text { identity - believes the male to } \\
\text { be an effeminate male, gay, } \\
\text { and a 'Drag Queen' }\end{array}$ \\
\hline \multicolumn{3}{|l|}{ Train station in known 'Gay' suburb } \\
\hline Vignette (2) & Vignette (4) & Vignette (6) \\
\hline $\begin{array}{l}\text { Motivation unspecified - beliefs } \\
\text { in victims } S / S / G \text { identity } \\
\text { unspecified as no words were } \\
\text { exchanged during the assault }\end{array}$ & $\begin{array}{l}\text { Motivation due to negative } \\
\text { perception of male's } S / S / G \\
\text { identity- believes the male to } \\
\text { be an effeminate male, gay, } \\
\text { and a 'Drag Queen' }\end{array}$ & $\begin{array}{l}\text { Motivation due to negative } \\
\text { perception of male's } S / S / G \\
\text { identity - believes the male to } \\
\text { be an effeminate male, gay, } \\
\text { and a 'Drag Queen' }\end{array}$ \\
\hline \multicolumn{3}{|l|}{ (RER) location-specific } \\
\hline Control Vignette & Vignette (3) & Vignette (5) \\
\hline $\begin{array}{l}\text { Motivation unspecified - belief } \\
\text { in victims R/E/R unspecified } \\
\text { (Control) as no words were } \\
\text { exchanged during the assault }\end{array}$ & $\begin{array}{l}\text { Motivation due to R/E/R - belief } \\
\text { the male train station kiosk } \\
\text { worker to be an Orthodox } \\
\text { Russian Jew }\end{array}$ & $\begin{array}{l}\text { Motivation due to } \mathrm{R} / \mathrm{E} / \mathrm{R} \text { - belief } \\
\text { the male train station kiosk } \\
\text { worker to be an Orthodox } \\
\text { Russian Jew }\end{array}$ \\
\hline Vignette (2) & Vignette (4) & Vignette $(6)$ \\
\hline $\begin{array}{l}\text { Motivation unspecified - belief } \\
\text { in victims R/E/R unspecified as } \\
\text { no words were exchanged } \\
\text { during the assault }\end{array}$ & $\begin{array}{l}\text { Motivation due to R/E/R - belief } \\
\text { the male train station kiosk } \\
\text { worker to be an Orthodox } \\
\text { Russian Jew }\end{array}$ & $\begin{array}{l}\text { Motivation due to R/E/R - belief } \\
\text { the male train station kiosk } \\
\text { worker to be an Orthodox } \\
\text { Russian Jew }\end{array}$ \\
\hline
\end{tabular}




\section{Police perceptions of prejudice: how police awareness training influences the capacity of police to assess prejudiced motivated crime}

\section{Toby Miles-Johnson, Lorraine Mazerolle, Sharon Pickering \& Paul Smith}

To cite this article: Toby Miles-Johnson, Lorraine Mazerolle, Sharon Pickering \& Paul Smith (2016): Police perceptions of prejudice: how police awareness training influences the capacity of police to assess prejudiced motivated crime, Policing and Society, DOI: 10.1080/10439463.2016.1206099

To link to this article: $\mathrm{http}: / / d x . d o i . o r g / 10.1080 / 10439463.2016 .1206099$

Published online: 05 Jul 2016.

Submit your article to this journal $\sqsubset$

à

View related articles $\square$

View Crossmark data ¿ 